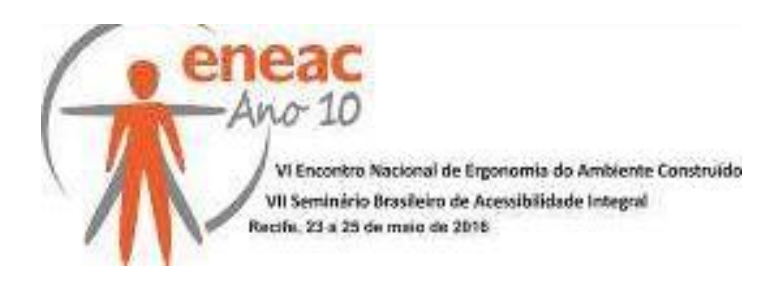

\title{
MÉTODO DE DESIGN DE INTERIORES NO BRASIL
}

\author{
OLIVEIRA, Gilberto (1) \\ MONT'ALVÃO, Cláudia (2)
}

(1) Pontifícia Universidade Católica do Rio de Janeiro (PUC-Rio), D.Sc. em Design, e-mail: grangeldesign@gmail.com

(2) Pontifícia Universidade Católica (PUC-Rio), D.Sc. Engenharia de Transportes e-mail: $\underline{\text { cmontalvao@puc-rio.br }}$

\section{RESUMO EXPANDIDO}

O método de projeto de interiores no Brasil é o objeto de estudo deste trabalho. Sabe-se da importância do uso de métodos adequados ao planejamento de ambientes e o uso dos conhecimentos da ergonomia para efetiva realização de um bom trabalho. $O$ presente resumo é resultado da tese de doutorado intitulada: Método de Design de Interiores no Brasil, uma contribuição dos princípios da ergonomia do ambiente construído, defendida e aprovada na Pontifícia Universidade Católica do Rio de Janeiro - PUC-Rio.

O estudo na sua fase teórica apontou quais são os componentes do problema de projeto de interiores no segmento residencial, os quais foram identificados e organizados em temas gerais de abrangência ampla: as necessidades do usuário, aspectos ambientais do espaço arquitetônico, aspectos ergonômicos do projeto e aspectos de ordem econômica.

Nesta mesma etapa também foram identificados os agentes, ou seja, os principais atores no processo de projeto de interiores que compõe o elenco prático dessa atividade. Fez-se uma revisão sobre as origens e atribuições dos profissionais envolvidos com o projeto de interiores, a saber: arquitetos, designers (produto) e designers de interiores, aqui tratados pela expressão coletiva: profissionais de DI. Fezse uma abordagem contemporânea considerando as legislações vigentes sobre as atividades destes profissionais e os limites de atuação de forma individualizada. 


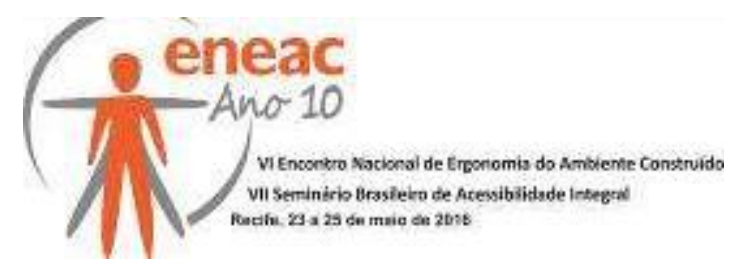

Complementou-se o assunto com a descrição dos agentes do projeto de interiores, apontando-se a importância do cliente no processo - o qual sob nenhuma hipótese deverá ficar relegado à periferia do trabalho. Entendeu-se que o cliente tem o direito em acreditar que o profissional de D.I. o protege da própria ignorância. Nesse sentido, prevalece uma relação de confiança mútua entre ambos. Da mesma forma que os profissionais muitas das vezes trabalham em equipe, o mesmo frequentemente ocorre com o cliente. Projetos de maior envergadura não envolvem apenas um cliente, e sim geralmente um grupo (que pode ser uma família, uma instituição ou ainda, um órgão público, ou privado). Por outro lado, sabe-se que o cliente enquanto contratante, nem sempre será o cliente final. Devido a essas questões a pesquisa tratou de distinguir as diferenças entre usuário, cliente e consumidor.

Entende-se que projetar é um fenômeno complexo, multidimensional, multidisciplinar, onde a carga da experiência e do conhecimento do profissional de design ou arquitetura, faz toda diferença. É uma atividade em que o profissional pode trabalhar isoladamente, ou dependendo da complexidade do projeto, com equipes de especialistas onde cada indivíduo desempenhará papeis bem específicos.

Considerando-se que os profissionais atuantes no segmento de design de interiores possuem formação acadêmica diferenciada entre si e portanto, fazem uso desse conhecimento na realização de sua atividade, fez-se um passeio sobre os principais métodos de projeto praticados pelos profissionais de D.I. A revisão realizada sobre esse assunto apontou de maneira geral, alguns princípios essenciais que permeiam a atividade de projeto de interiores, os quais chamou-se de pontos de similaridades: a compreensão do problema - o problema de projeto é por essência a própria razão da ação de projetar, uma vez que, parte-se de uma questão (ou situação) em busca de uma solução; a geração de alternativas - nesta etapa, comum a todos os métodos, refere-se a geração de ideias e possibilidades de soluções; a definição da alternativa escolhida - considerada por muitos profissionais como uma das etapas do processo de projeto, de maior dificuldade, principalmente por seu caráter necessariamente sintetizador.

Acredita-se que os princípios da ergonomia do ambiente construído podem contribuir com significativas melhorias na elaboração dos projetos de interiores. Más afinal, o que deve ser investigado ou observado? Para tratar desse assunto, descreveu-se os princípios básicos que devem ser considerados nos estudos de EAC: a interação do homem com o ambiente, o princípio da usabilidade, abordagem sistêmica, o enfoque centrado no usuário e garantir o conforto ambiental. Além disso, pesquisou-se quais métodos vem sendo aplicados e testados com mais frequência na busca de soluções e proposições para as não adequações aos princípios estabelecidos pela EAC. Desta forma, fez-se uma revisão dos principais métodos utilizados nesse segmento da ergonomia com foco na análise do usuário e do ambiente. 


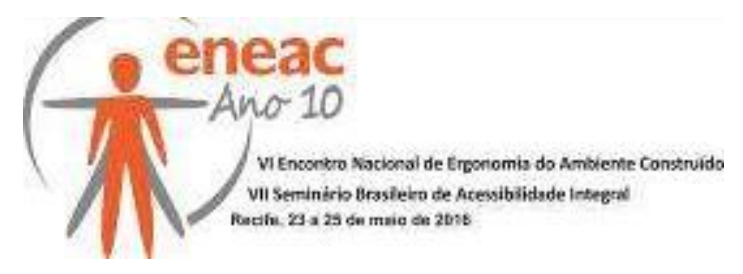

Destacou-se o caráter projetual principalmente nos três métodos (Intervenção Ergonomizadora - IE, Análise Macroergonômica do Trabalho - AMT e a Metodologia Ergonômica de Avaliação para o Ambiente Construído - MEAC), que já indicam - no próprio nome de uma de suas fases, a necessidade de desenvolvimento de um projeto: Projetação ergonômica - IE; Projetação ou desenvolvimento de soluções de melhoria AMT; Proposições ergonômicas para o ambiente - MEAC. Esse caráter denota a importância e a necessidade da atuação de profissionais de projeto (designers, arquitetos), que utilizarão seus próprios métodos de criação para atender a essa demanda de origem ergonômica. Nesse sentido, implica um olhar mais cuidadoso sobre quais metodologias (os profissionais de projetos) propõe para seus clientes (usuários) mediante a demandas de origem ergonômica. Constatou-se que a expertise utilizada nos métodos revisados, contribuiu significativamente com sugestões de técnicas e instrumentos para possíveis melhorias no exercício projetual da atividade de design de interiores.

A fim de compreender como ocorre o processo projetual da atividade objeto deste estudo, realizou-se pesquisa descritiva - etapa prática da pesquisa, junto a profissionais de D.I. e usuários que contrataram tais serviços. Inquiriu-se 85 (oitenta e cinco) profissionais de praticamente todas as capitais brasileiras e 32 (trinta e dois) usuários que passaram pela experiência de contratar um projeto de interiores e o implantou na sua integralidade.

Após análise e interpretação dos dados levantados identificou-se que os profissionais de D.I. em sua maioria fazem uso de alguma estrutura metodológica, onde predomina a técnica de entrevista aberta (ou conversa informal) para as principais ações e/ou etapas do processo de projeto de interiores a saber: ponto de partida para um novo trabalho, identificação de necessidades, desenvolvimento de soluções, tratamento de adversidades, apresentação de proposta e avaliação final do trabalho. Por essa razão, contatou-se que a experiência e a habilidade do profissional são fundamentais para um bom trabalho.

Também identificou-se um número significativo de profissionais que afirmaram conhecer os principais aspectos da ergonomia e asseguraram que fazem uso deste conhecimento predominantemente na fase projetação. Embora os resultados sejam positivos, percebese sensível ausência de sistematização dos processos. Observou-se que há índices consideráveis de retrabalho. Verificou-se também na pesquisa descritiva que o conceito de Usabilidade, estabelecido pela ISO 9241, é apontado (pelos próprios inquiridos) com ocorrência parcial nos projetos realizados pelos profissionais de D.I.

$\mathrm{Na}$ inquirição com os usuários a entrevista aberta (conversa informal) também está presente nas principais fases do projeto: fase inicial, identificação de necessidades, tratamento de adversidades, avaliação do trabalho final. Detectou-se na investigação junto aos usuários as seguintes não conformidades: (1) inadequada identificação das necessidades dos usuários, (2) ausência parcial de verificação sobre a satisfação do 


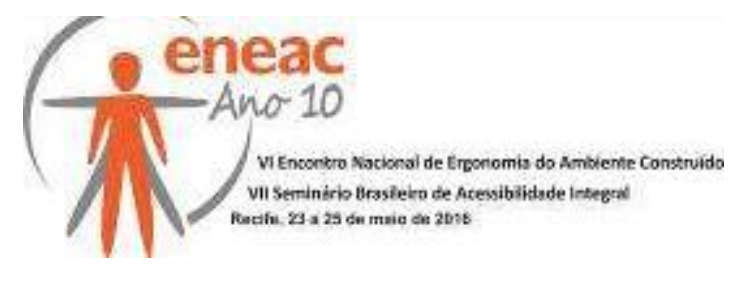

usuários, (3) alguns projeto com falhas finais de execução e (4) ausência de processo metodológico sistemático e rigoroso.

Diante do desafio proposto aos profissionais - transpor para o papel as necessidades que os usuários almejam, acredita-se que algumas ferramentas são essenciais na elaboração de um método projetual. Propôs-se ao final da pesquisa, uma estrutura metodológica apoiada em procedimentos existentes, praticados por profissionais de D.I. que contemplem de maneira diferenciada os princípios da ergonomia do ambiente construído. Nesse sentido, planejou-se as seguintes ações: (1) reorganizar as etapas gerais do processo projetual de interiores; (2) agregar novas etapas ou fases; (3) detalhar o uso de ferramentas (ou técnicas) que contribuam de forma positiva na identificação das necessidades dos usuários; (4) realizar a etapa de validação; (5) estabelecer pontos de revisão (retorno), caso alguma etapa não esteja plenamente atendida.

Os propósitos da pesquisa realizada, bem como as críticas e observações levantadas, visam exclusivamente a busca contínua pela melhoria na prestação de serviços realizados pelos profissionais de D.I. e a plena satisfação dos usuários.

\section{AGRADECIMENTOS}

Pontifícia Universidade Católica do Rio de Janeiro - PUC - Rio.

LEUI - Laboratório de Ergonomia e Usabilidade e Interfaces - PUC-Rio.

FAPEMA - Fundação de Amparo à Pesquisa e ao Desenvolvimento Científico do Maranhão. 